\title{
Assessment Strategy in Mathematics for Second Language Learners
}

\author{
Petro Erasmus \\ North West University, South Africa
}

\begin{abstract}
Mathematics achievement at school is one of the best predictors of success at tertiary level and thus of cardinal importance to any developing country. Second-language learners who attend English medium schools find themselves in situations which places high demands on them in order to process loads of information to master not only the English language, but mathematics concepts and to apply their mathematics knowledge in other subjects. Language discourses much of what manifests in the mathematics classes. The proposed comprehensive assessment strategy to assess and handle English second language learners problems in mathematics is based on an assessment of a) cognitive facets; $b$ ) hidden and visible affective facets c) meta-cognitive functioning. This model is based on results of two QUANTITATIVE/qualitative study ( $n=435$ Grades 9 and 11 learners); ( $n=682-$ Grades 3, 4 and 5) aimed at exploring possible predictors of second language learners' mathematics achievement and several case studies.
\end{abstract}

\section{Introduction}

Mathematical performance is of the utmost importance in any developing country. Research has indicated that mathematical performance at school is one of the best predictors of success at tertiary level and that there is a statistical, meaningful correlation between mathematical achievement and aspects of study orientation in mathematics [2] [3] [15].

Research has focused on the influence of various factors that could possibly predict mathematical achievement, such as social, cognitive, metacognitive, conative and affective facets of achievement in mathematics [4] [6]. Research on the role of emotional intelligence in school achievement has according to Bar-On proven time and again that performance at school, aptitude and IQ predicts only $9 \%$ of learners' future success [5]. There are many factors that play a significant role in the mathematics achievement of second language learners which can be identified within the learner, their experience of the teaching in mathematics, the classroom atmosphere and their family life [4] [8] [10].

This assessment strategy aims to identify the gap between the second language learners levels of mathematics achievement on the one hand, and the level at which the second language learners are able to realize their potential in mathematics on the other hand, by focusing on factors that can be identified within the learner, and the mathematics subject content.

\section{Definition of a number of key concepts}

\subsection{Second-language learner}

The concept second-language learner for the purpose of this study refers specifically to the learner who receives formal training in English, but whose home language is any other language other than English.

\subsection{Assessment}

Assessment refers to the measurement of present state of the learners functioning with regards to the subject mathematics. It aims to measures the effect of teaching and learning, it makes grading possible, it provides information that forms the basis for differentiation and promotion, it gives a concrete image of abstract learning and it gives an indication of the suitability of the curriculum [1] [17].

\subsection{Study orientation in mathematics}

Study orientation in mathematics is related to mastering new concepts in the mathematics curriculum and includes the following dimensions: Problem-solving behavior, Study habits, Attitude towards mathematics, Study milieu, Information processing and Mathematic anxiety [9] [10]. According to Maree, Fletcher, \& Sommerville there is a statistically significant correlation between mathematics achievement and aspects of study orientation in mathematics [11].

\subsection{Emotional intelligence}

Emotional intelligence plays a role not only in learners' academic success, but also in the adult's success in the workplace and martial relationships and refers to the following factors: Interpersonal skills, Intrapersonal skills, Stress management, Adaptability and General mood [7] [12] [13]. 


\subsection{Mathematics resilience}

Mathematics resilience can be defined as a positive adaptive stance to mathematics which allows students to continue learning despite adversity [19].

\subsection{Mathematics achievement}

Mathematics achievement refers to the percentage obtained in the final end-of-the-year mathematics assessment.

\subsection{Metacognition}

Metacognition can be explained as the knowledge of the human mind and of the range of [20]. It is the ability of the individual to monitor his/her own current level of understanding and decide when is not adequate, and can be simply put the process of thinking of one's own thinking.

\section{Previous Studies}

\subsection{Designing a Remedial Strategy in mathematics for second language learners}

This quantitative study $(n=677)$ aimed to design a remedial strategy that could improve the identification and management of problems in mathematics to such an extent that it could lead to a significant reduction in second language learners' mathematical problems and to more adequate performance in mathematics. By using a quota sampling method 677 grades 3, 4 and 5 learners from four English medium schools were selected to participate in this study.

All participants completed the following questionnaires:

- Learner questionnaire: This questionnaire containing 50 items was initially compiled for the second-language learners [1]. The overall aim of this questionnaire was to determine whether the following aspects: remedial assistance in mathematics, mathematics self-confidence and study attitude towards mathematics played a role in the mathematics performance of the second language user. The reliability coefficient (Cronbach alpha) for the Learner questionnaire lies between 0.52 and 0.74 and may be regarded as highly satisfactory for the purposes for which the questionnaire was used [16]

- Mafikeng diagnostic tests: The Mafikeng diagnostic tests implemented in this study was based on the Diagnostic tests compiled by the University of Stellenbosch (Author and date of publication unknown). The language and items were adapted for the learners who are taught through medium of a second language. The test had five subsections:
Mental arithmetic (No language), Mental arithmetic (Language), Mechanical operations (No language), Word sums (Language) and Notation and place value (Language). The diagnostic tests for the different grades contain the same subsections and types of items, but they differed in respect of degrees of difficulty [16]

The research focused on the association between the performance of the different age groups (Grades 3, 4 and 5) and the two genders in the Mafikeng diagnostic test and the Learner questionnaire. The following statistical procedures were inter alia performed to investigate the hypothesis: factor analysis, item analysis and post hoc comparisons.

\subsection{Relationship between emotional intelligence, Study orientation in mathematics and the mathematics achievement of the middle adolescent -}

The goal of this mixed method study $(n=435)$ of 435 Grades 9 and 11 learners from three English medium schools in the Mafikeng area was to investigate the nature of emotional intelligence and study orientation in mathematics, as well as the nature and meaning of mathematics achievement and sought to answer the following two questions: To which extent does a combination of facets of emotional intelligence and study orientation predict the mathematics achievement of middle adolescents and what were the comparisons between the performance of the different language, gender, and age groups represented in this study.

All participants completed the following measures:

- The Emotional Quotient Inventory: Youth Version $(E Q-i: Y V)$ was used to measure emotional intelligence [13]. The five-factor structure of the $(E Q-i: \quad Y V)$ namely Interpersonal, Intrapersonal, Stress management, Adpatibility and General mood scales) emerged through an exploratory factor analysis of the total normative sample. Internal reliability (Cronbach's) varied between 0.67 and 0.90 [13]. The advantages of using the Bar-On (EQ-i) is that it is the only available measurement of emotional intelligence that has the validity and norms to allow for its use in a variety of settings such as recruitment and school environment to name but a few [7].

- Study orientation in mathematics (SOM) comprises of six subtests containing 92 items that relate to how individuals feel or act regarding aspects of their achievement in mathematics [10]. The Cronbach alpha reliability coefficients for the different subtests of the questionnaire range from .70 to .80 and for the questionnaire as a whole from .89 to .95 . 
- A non-standardised, structured questionnaire was administered to obtain the respondents' demographic data Qualitative data was gathered by means of focus group interviews, semistructured interviews (with both learners and teachers), observation of participants during interviews and field notes as well as a reflective journal that was kept by the researcher [14]. All responses were recorded on tape [15].

\section{Results of previous studies}

\subsection{Designing a Remedial Strategy in mathematics for second language learners -}

The role of language in mathematics achievement was emphasized by the results of the first study that indicated that the medians of the Grade 4 second language learners in the subsection (Mental arithmetic - where language plays a role) were statistically significant lower than the medians for the Grades 3 and 5 [1]. This implies that the mathematics performance of the Tswana learner in Grade 4 will be affected negatively if the learner has a reading problem, because mathematics in Grade 4 requires a higher degree of reading proficiency than the lower grades [16]. Sentson states that when a learner is taught mathematics in another language other than their mother tongue, it is not only the learner's proficiency in this second language that affects the nature and quality of learning, but very importantly their proficiency in their mother tongue as well [18]. Mugisha stresses the relationship between language proficiency and mathematics achievement in that learners who have a good command of mathematics language and a good command of the language of instruction do better in mathematics than those who don't.

The results of this study stressed the importance of a mathematics portfolio for the establishment of a permanent record of the second language learners' comprehension of mathematical concepts. The use of questionnaires and diagnostic tests are of utmost importance in compiling said portfolio. The following tests/assignments of the learners may inter alia be used for diagnostic analysis: informal tests, standardized or formal tests, schoolbooks of the learners, work assignments and all other tests, examinations and other forms of assessment and evaluation.

\subsection{Relationship between emotional intelligence, Study orientation in mathematics and the mathematics achievement of the middle adolescent}

- The result of the final stepwise regression model used it he stud explained the mathematics achievement of the Grade 9 group who participated in this study significantly $(F=27.384 ; p<0.001)$. The coefficient of determination (R2) was .335 which means that approximately one-third of the variability in the mathematics achievement of the Grade 9 group can be explained by a linear combination of dimensions of SOM (Study habits, Mathematics anxiety) and facets of EQ (General mood and Adaptability) (See Table 1).

- The final regression model for the Grade 11 group also explained mathematics achievement significantly $(\mathrm{F}=21.125 ; \mathrm{p}<0.001)$. The coefficient of determination was (R2) was .294 which means that $29.4 \%$ of the variance in the mathematics achievement of the Grade 11 group can be explained by a linear combination of Information process, Problem solving, Intrapersonal skills and Adaptability.

- Mathematics anxiety was the most important predictor of mathematics achievement for the Grade 9 group, followed by Study habits, General mood and Adaptability. For the Grade 11 group, Information processing was the most important predictor of mathematics achievement, followed by Problem-solving, Intrapersonal skills and Adaptability.

The implementation of questionnaires such as the SOM to measure study orientation in mathematics, and the $E Q-i: Y V$ to measure emotional intelligence at the beginning of a school year can provide teachers and remedial teachers with invaluable information regarding each learner's level of affective functioning.

\section{Assessment strategy in mathematics for second language learners}

The proposed assessment strategy in mathematics for second language learners (Figure 1) in this study focuses on the following three aspects: cognitive facets, affective facets and screening tests.

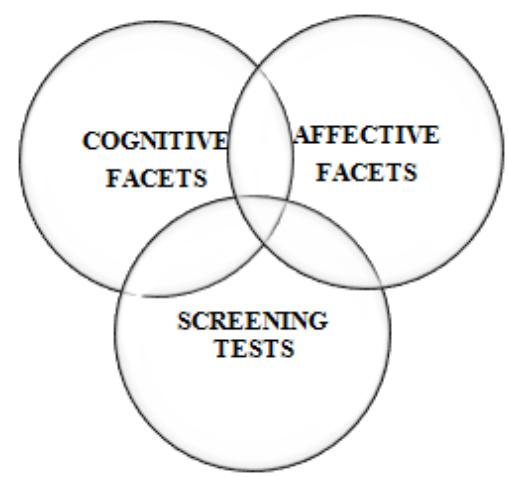

Figure 1. Proposed assessment strategy in mathematics for second language learners Screening tests, Cognitive facets and Affective facets 
Table 1. Comparison of the predictors of mathematics achievement according to grades (Grade 9 / Grade 11)

\begin{tabular}{|c|c|c|c|}
\hline Grade & Significant predictors & $\begin{array}{l}\text { Regression } \\
\text { coefficients }\end{array}$ & $\begin{array}{c}\text { Standardized } \\
\text { Regression } \\
\text { coefficients }\end{array}$ \\
\hline \multirow[t]{4}{*}{9} & Mathematics anxiety & .209 & $.358 * *$ \\
\hline & Study habits & .280 & $311^{* *}$ \\
\hline & General mood & -.284 & $-.213 * *$ \\
\hline & Adaptability & .239 & $.167 *$ \\
\hline \multicolumn{4}{|c|}{$\mathrm{R}^{2}=335 ; *: \mathrm{p}<.05 ; * *: \mathrm{p}<.01$} \\
\hline \multirow[t]{4}{*}{11} & Information processing & .227 & $372 * *$ \\
\hline & Problem solving & .086 & $.148 *$ \\
\hline & Intrapersonal & -.180 & $-.167^{*}$ \\
\hline & Adaptability & .204 & $.086 *$ \\
\hline \multicolumn{4}{|c|}{$\mathrm{R}^{2}=.294 ; * \mathrm{p}<.05 ; * * \mathrm{p}<.01$} \\
\hline
\end{tabular}

Screening tests in mathematics and reading (See Figure 2) aims to measure the learners' competency in the four basic calculations - addition, subtraction, multiplication and division; and the learners' reading speed and graded reading aimed at assessing the difficulty of words that the learner can read. These screening tests further assesses the learners' visual motor speed as well as their work tempo with regards basic calculations in mathematics and their tempo with which they can code and encode the alphabet used in reading. The teacher and/or remedial therapist can identify mistakes due to language problems; mistakes due to learner not mastering the basic mathematical concept, skills and facts, mistakes due to faulty associations and rigid thinking processes, mistakes due to implementing irrelevant rules or strategies, mistakes due to learner experiencing problems with acquiring spatial information.

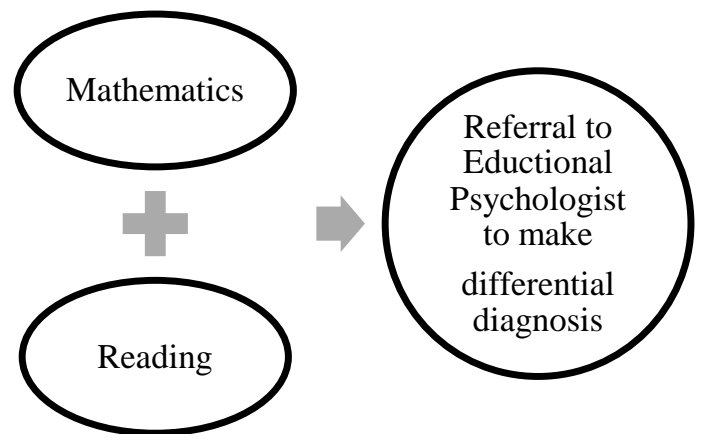

Figure 2. Screening tests
Another aim of the screening test is identify learners with possible learning disabilities and developmental delays and make referrals to en Educational Psychologist to assess for possible childhood disorders such as dyslexia, dysgraphia and dyscalculia and other childhood disorders such as Attention deficit disorders with and without Hyperactivity to name but a few. The results of these psychological assessments will identify learners who qualify for special assessment arrangement such as extra time, assessment in separate venue and a scribe, or other concessions as stated in the Education Law.

Cognitive facets: The following tests/assignments of the learners may inter alia be used for diagnostic analysis: informal tests, standardized or formal tests, schoolbooks of the learners, work assignments and all other tests, examinations and other forms of assessment and evaluation. The results of the assessments of the cognitive factors will enable the teachers and remedial teachers/therapists to compile an individualized education intervention programme for the individual learner, but also to compile a intervention programme for a group of learners. 


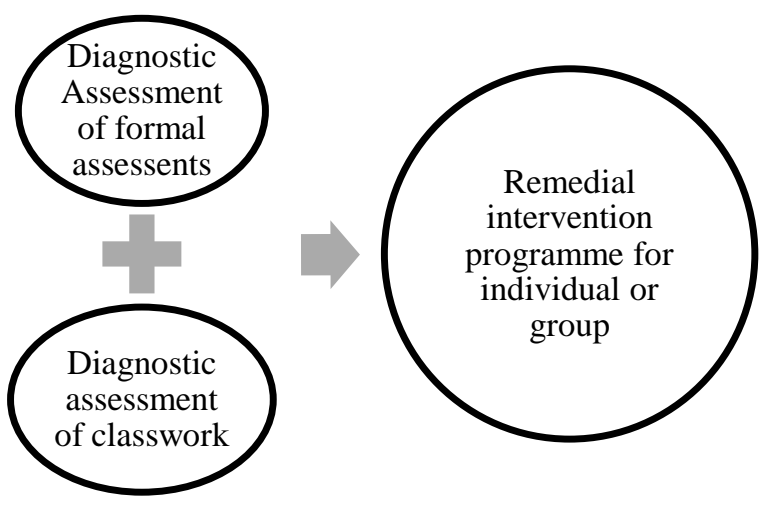

Figure 3. Cognitive facets

Affective facets as put out in Figure 4 indicates which questionnaires can be implemented to assess affective factors and should include the following: Resilience, Study orientation in mathematics, Emotional intelligence and Meta-cognitive skills. The profiles that can be compiled from the results of these questionnaires that can be implemented at the beginning of the year will enable the teacher and remedial therapist to identify learners who will benefit from individual therapy as well as helping group of learners to become aware of the importance of study orientation in mathematics, effective functioning with regards emotional intelligence, the importance of meta-cognitive skills in processing mathematical information and the role of resilience in their lives.
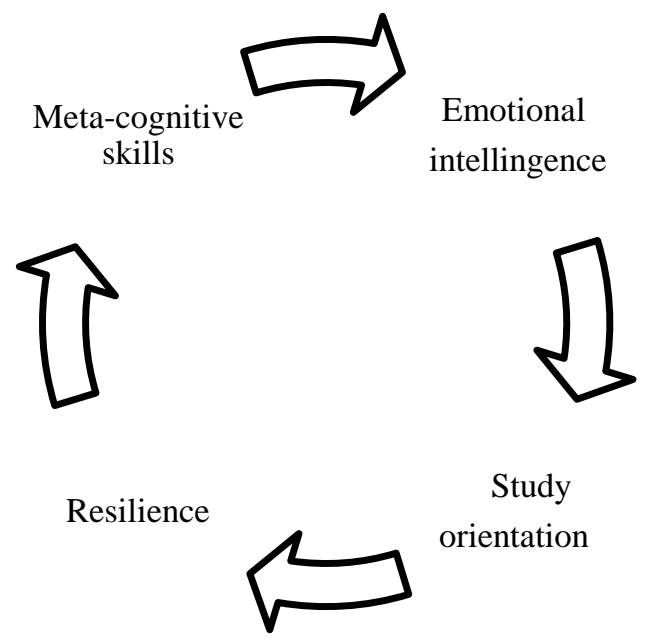

Study

orientation

Figure 4. Aspects within the learner including affective facets

\section{Conclusion}

The findings of the two studies (Designing a remedial strategy in mathematics for second language users, and the second study, and The relationship between emotional intelligence, study orientation in mathematics and the mathematics achievement of the middle adolescent) suggest that the administration of questionnaires on emotional intelligence and study orientation in mathematics can provide the teacher with valuable information regarding the learners present functioning, and enable the teachers to plan strategies to address possible gaps. The results of the first study addresses the importance of a diagnostic assessment as a tool to enable the teacher to identify gaps in the individual learners'/ and or group of learners mathematical knowledge (conceptual development).

This proposed assessment strategy aims to identify the gap between the second language learners levels of mathematics achievement on the one hand, and the level at which the second language learners are able to realize their potential in mathematics on the other hand, by focusing on assessment of Cognitive facets(Diagnostic assessments), Affective facets (Emotional intelligence, Study orientation and Resilience, as well as Meta-cognitive functioning) and Screening tests that can be implemented to ensure early identification of learners who should be referred for a comprehensive assessment by and educational psychologist.

\section{References}

[1] C.P. Erasmus, "Die daarstel van 'n remediëringstrategie in Wiskunde vir Tswanasprekende leerders" (The design of a remedial strategy in mathematics for Tswana-speaking learners) (Unpublished master's dissertation). University of Pretoria, South Africa, 2002.

[2] J.G. Maree, "Die uitdaging van ontoereikende wiskundeprestasie: Fokus of metabenadering" [The challenge of inadequate achievement in mathematics: Focus on a meta-approach]. South African Journal of Natural Sciences and Technology, 2009, pp. 265-287.

[3] J. Leppävirta, The impact of maths anxiety on the performance of students of electromagnetics" Journal of Engineering Education, 100(3), 2011, pp. 424-443.

[4] M.S. Van der Walt, "Studieoriëntasie en basiese woordeskat in wiskunde in die laerskool" [Study orientation and basic vocabulary in mathematics in the primary school.] South African Journal of Natural Sciences and Technology, 24, 2009, pp. 378-392

[5] R. Bar-On, "The Bar-On model of emotional-social intelligence (ESI)" Psicothema, 11, 2006, pp. 13-25.

[6] P.R. Pintrich, "The role of metacognitive knowledge in learning, teaching and assessing" Theory into Practice, 41(4), 2002, pp 219-225.

[7] G. Bharwaney, Emotionally intelligent living (rev. edn.): Strategies for increasing your EQ, Crown House, London, 2007. 
[8] A.R. Damasio, "Descartes error: Emotion, reason, and the human brain”, G.P Putnam Sons, New York, 1994.

[9] J.G. Maree, J.M. Molepo, J.H. Owen, and R. Ehlers, "'n Probleemgebaseerde benadering tot wiskunde in graad 9 en graad 11 in die Limpopo provinsie", Suid-Afrikaanse Tydskrif vir Natuurwetenskap en Tegnologie, 24(4), 2005, pp. 124-133.

[10] J.G. Maree, "Die ontwerp en evaluering van ' $n$ studieoriënteringsvraelys in wiskunde", [The design and evaluation of a study orientation in maths] $\mathrm{PhD}$ proefskrif, University of Pretoria, Pretoria, 1997.

[11] J.G. Maree, L. Fletcher, and J. Sommerville, "Predicting success among prospective first-year students at the University of Pretoria", South African Journal of Higher Education, 25, 2011, pp. 1125-1139

[12] D. Louw, and A. Louw, "Child and adolescent development" University of Free State, Bloemfontein, 2007.

[13] R. Bar-On, and D.A. Parker, "The handbook of emotional intelligence; Theory, development, assessment, and application at home, school, and in the workplace", Jossey-Bass, San Francisco, CA, 2000.

[14] J.G. Maree, L. Fletcher, and P. Erasmus, "The relationship between emotional intelligence, study orientation in mathematics and the mathematics achievement of the middle adolescent", Journal of Psychology in Africa, 23(2), 2013, pp. 205-212.

[15] C.P. Erasmus, "Die verband tussen emosionele intelligensie, studie-oriëntasie in wiskunde, en die middeladolessent se wiskundeprestasie" [The relationship between emotional intelligence, study orientation in maths and mathematics achievement of the middle adolescent] [Unpublished doctoral thesis], University of Pretoria, Pretoria, 2013.

[16] J. G. Maree, and C. P. Erasmus, "Mathematics skills of Tswana-speaking learners in the North West Province of South Africa", International Journal of Adolescence and Youth,13(1-2), 2006,71-97.

[17] R.A. Krüger, “Beginsels en kriteria vir kurrikulumontwerp”, HAUM, Pretoria, 1980.

[18] C. Sentson, "The effect of language of presentation on pupils' performance in a mathematics test", South African Journal of Education, 14(3), 1994, 109-115.

[19] S. Johnston-Wilder, and C. Lee, "Mathematical resilience", Mathematics Teaching, 218, 2010, pp. 33-41.

[20] C.K. Sigelman, \& E.A. Rider, "Life-span human development $\left(6^{\text {th }}\right.$ ed.).". Belmont, Wadworth, 2009. 